\title{
Influences of indigenous language on spatial frames of reference in Aboriginal English
}

\author{
Cris Edmonds-Wathen
}

Received: 5 September 2012 / Revised: 23 January 2013 / Accepted: 11 November 2013 / Published online: 27 November 2013

(C) Mathematics Education Research Group of Australasia, Inc. 2013

\begin{abstract}
The Aboriginal English spoken by Indigenous children in remote communities in the Northern Territory of Australia is influenced by the home languages spoken by themselves and their families. This affects uses of spatial terms used in mathematics such as 'in front' and 'behind.' Speakers of the endangered Indigenous Australian language Iwaidja use the intrinsic frame of reference in contexts where speakers of Standard Australian English use the relative frame of reference. Children speaking Aboriginal English show patterns of use that parallel the Iwaidja contexts. This paper presents detailed examples of spatial descriptions in Iwaidja and Aboriginal English that demonstrate the parallel patterns of use. The data comes from a study that investigated how an understanding of spatial frame of reference in Iwaidja could assist teaching mathematics to Indigenous language-speaking students. Implications for teaching mathematics are explored for teachers without previous experience in a remote Indigenous community.
\end{abstract}

Keywords Indigenous Australian language $\cdot$ Remote $\cdot$ Language and cognition $\cdot$ Spatial frames of reference $\cdot$ Aboriginal English

\section{Introduction}

Language is a crucial factor in the learning of mathematics. Assessed in Standard Australian English, Indigenous students whose home languages are Australian languages ${ }^{1}$ have lower numeracy achievement than those who speak Standard Australian English (Frigo et al. 2004). Linguistic factors in learning mathematics include differences in semantic structure between the languages of home and school as well as fluency issues (Berry 1985; Watson 1988).

\footnotetext{
${ }^{1}$ A language which has its origin in Australia, from an Australian language family, spoken by the Indigenous peoples of Australia. In education in Australia, these are often called Indigenous languages.
}

C. Edmonds-Wathen $(\triangle)$

School of Education, Charles Darwin University, Darwin, Australia

e-mail: cris.edmonds-wathen@cdu.edu.au 
There is a remarkable diversity in the ways that different languages talk about space that may be unexpected for those who see spatial language as reflecting a perceptual apprehension of the world (Levinson 2003). Such diversity has implications for mathematics teaching and learning in multilingual environments, especially where the language of instruction and of the teachers is different to the home languages of the students. The way that space is conceptualised and talked about in the mathematics curriculum and by teachers may be different to the way it is conceptualised and talked about by students.

This paper considers the influence of Australian languages on the expression of spatial concepts in the English spoken by a group of Indigenous language-speaking children at Minjilang Community, Croker Island, in Northwest Arnhem Land, Northern Territory. It focuses on the terms in front and behind, and the semantically related front and back. Teachers at Mamaruni School, Minjilang, reported difficulties with the uses of locational words in the classroom. For example, one teacher said, "If you say 'behind the bin' you'll still find, you know, some kids may be in front of the bin ... so there's a lot to still work on with the language aspect." These concepts of 'in front' and 'behind' are related to those of 'before' and 'after' and are essential parts of the everyday and mathematical language of position and transformation, as well as part of understanding sequencing in terms of the number line (Edmonds-Wathen 2012b).

The focus of this paper is data that emerged from a study investigating spatial frames of reference in Iwaidja, one of the Australian languages spoken at Minjilang. The overall study was ethnographic in approach, combining extensive observation in the school, practitioner research as a part-time teacher in the school, teacher interviews, elements of action research, document analysis, and a set of targeted cognitive linguistic quasi-experimental tasks. The data reported here come from a task designed to elicit frame of reference uses to describe and match spatial stimuli (Cognitive Anthropology Research Group [CARG] 1993).

Spatial frames of reference are ways of referring to how things are located with respect to each other. Cross-linguistic studies of spatial language and cognition are important for mathematics education because mathematics curricula in Australia contain assumptions about developmental sequences of spatial concept acquisition (Edmonds-Wathen 2011a). These assumptions appear to originate in the order of acquisition of spatial concepts in European languages (Johnston and Slobin 1979; Levinson 2003). Understanding differences in uses of spatial frames of reference may assist English-speaking teachers of mathematics to students from non-European language backgrounds.

The concepts focused on in the present paper, 'in front' and 'behind,' were identified as being of interest when the study showed differences in frame-of-reference uses of similar terms between Iwaidja and Standard Australian English. The data suggest that the children's uses and understandings of these terms in English may be the result of the influence of Iwaidja or other Australian languages on the variety of English spoken by the children.

\section{Remote teaching in the Northern Territory}

The Northern Territory has by far the greatest proportion of Indigenous languagespeaking students of any jurisdiction in Australia (Australian Bureau of Statistics 2011). 
In many remote schools all or most students speak Australian languages at home and many begin school with little or no English. Provision for this includes an English as a Second Language (ESL) section of the Northern Territory Curriculum Framework, which has been designed with Indigenous language-speaking students in mind (Northern Territory Department of Education and Training [NT DET] 2009) and the employment of local Indigenous assistant teachers whose role include translation between teacher and students (Moses and Wigglesworth 2008).

However, teachers in remote schools in the Northern Territory tend to be young and relatively inexperienced and often have no formal training in teaching ESL (Cooper et al. 2004; Skilbeck and Connell 2003; Thornton et al. 2011). Many of them come from other states and before their posting may never have met an Indigenous person, nor heard a living Australian language spoken. This was the case with the teachers at Mamaruni School, all of whom were new to the school and none of whom had training in teaching ESL. One of the teachers involved in the study had taught in other Indigenous communities but that had been nearly 20 years previously.

At Mamaruni School almost all the students are multilingual Indigenous children who speak a range of Australian languages as their first or home languages. The teachers found not sharing a common language fluently with their students to be one of the most significant factors affecting their mathematics classrooms, but they had little appreciation of conceptual and grammatical differences between languages. The teachers at Mamaruni School also had little knowledge of the variety of English spoken by their students, since their main concern was improving and assessing their students' competence in Standard Australian English.

Some teachers at Mamaruni School banned the use of home languages in the classroom. Reasons stated included the priority for students to learn English and to prevent teasing between students. The latter point relates to the feeling of loss of control which Jorgensen (2011) notes amongst teachers in the Kimberley region of Western Australian when they do not understand what their Indigenous students are talking about. Banning home languages was supported by the Northern Territory Government's (2009) Compulsory Teaching in English for the first four hours of each school day Policy which mandated that all teaching in the prime teaching time be in English. This policy, which went against what is known about the cognitive benefits of being schooled in a language in which one is fluent (Cummins 1979, 1989; Silburn et al. 2011) and which met widespread opposition on the part of schools, community members, language experts and others (Devlin 2011; Standing Committee on Aboriginal and Torres Strait Islander Affairs 2012), was replaced in July 2012 with one that recognises that "Home/local languages can and should be used where appropriate to support the learning and acquisition of concepts" (NT DET 2012, p.1).

Insisting that all teaching be in English does not necessarily mean that students will acquire the conceptual and semantic structures of Standard Australian English. Aboriginal English is the name for any of the varieties of English spoken by Indigenous Australians who also speak Australian languages. Aboriginal English is also the first language of many Indigenous Australians. Aboriginal English both performs an important identity function for Indigenous people and also allows Indigenous people to express their own concepts and worldviews in ways that are not possible in Standard Australian English (Butcher 2008; Konigsberg and Collard 2002; Malcolm et al. 2003). The relative inexperience of many teachers in remote schools regarding dialectal 
differences and Indigenous cultures may mean that they interpret Aboriginal English as substandard English (Butcher 2008; Frigo et al. 2004). This appeared to be the case at Mamaruni School, where students' English was assessed as beginner learner's English rather than as a distinct variety. In this way, differences between the Standard Australian English desired in the curriculum and the way the children spoke were assessed as inadequacies on the part of the children.

\section{Language use at Minjilang}

Minjilang is a multilingual community in Northwest Arnhem Land. The most widely spoken languages are Iwaidja, Mawng, Kunwinjku and English. In this part of Australia's Northern Territory, multilingualism is an integral part of a society (Evans 2010). Clan ownership of languages and traditional kinship laws which require marriage outside the clan mean that marriages are frequently between people of different language groups. Children thus grow up learning their parents' and grandparents' languages.

It is difficult to acquire accurate details of language use in the community. People claim greater or lesser proficiency than their actual proficiency in a language for complex social reasons. People can be reluctant to admit proficiency in a language to which they do not have clan rights and also reluctant to admit that they do not speak a language which they should speak (Evans 2010). Additionally, in casual speech people are likely to switch rapidly between three or four languages, depending on the shared repertoire of the interlocutors. Whether a stable mixed variety will emerge is not yet clear. However, I have heard both children and adults describe talk at Minjilang as "mixed-up." For outsiders, it is thus difficult to ascertain an individual's linguistic repertoire either by asking or by observing.

Today, Iwaidja is considered to be the language of Croker Island and is the main language of the older Traditional Owners. The original language of the island, Marrku, is almost extinct. Because of language shift, Iwaidja is seriously endangered. Kunwinjku and Mawng are more widely spoken, particularly in the younger age groups. Kunwinjku in particular appears to be gaining strength and speakers. It is not closely related to Iwaidja. However, Kunwinjku speakers and Iwaidja speakers share culture and ceremony, and frequently intermarry, as do Mawng speakers and Iwaidja speakers. There is a strong probability that similar worldviews amongst speakers of the two languages also result in similar conceptual expression in the languages.

Iwaidja was chosen as the focus for the study because there were established avenues for collaboration with experienced Iwaidja language consultants through the Iwaidja Documentation Project (Iwaidja Inyman 2010) and because it is the language of the Traditional Owners. Children at Minjilang speak and understand Kunwinjku, Mawng and English to varied extents and with varied proficiencies. The study revealed that although some children understand Iwaidja, none of them can speak it with confidence. Focusing on Kunwinjku or Mawng would have been more directly relevant to the educational context, since more children speak those languages, but was not logistically and politically feasible at Minjilang at the time.

English is spoken throughout Minjilang community in the school, the clinic and the Shire office, as well as being heard on television, music videos and DVDs. Some local 
families now speak English at home, which tends to be a variety of Aboriginal English which I call Minjilang English. It varies from the Standard Australian English taught in the school in terms of sound system, grammar and vocabulary.

Minjilang English appears to be an established variation of English rather than an innovation of the present generation of children. It shares common features of other varieties of Aboriginal English such as the lack of the copula verb "is" (Butcher 2008). Like Kriol, it uses the bin past tense marker. There are some features which I have not found in other varieties of Aboriginal English, such as the use of where as a locative preposition, for example, look where bag 'look in the bag'. This is widespread in Minjilang English and parallels the uses of the Iwaidja locative preposition wuka 'in/on/at/near.'

\section{Spatial language}

Spatial cognition and language are important mathematically not just in areas that are obviously spatial such as mapping and geometry. Spatial thinking also underpins many important numerical and logical processes such as managing information and solving number or algebraic problems (Booth and Thomas 1999; Huttenlocher 1968; Lean and Clements 1981; Wheatley 1998). Pimm (1991) notes that spatial encoding principles such as symbol order, position, relative size and orientation are more significant in written mathematics than in written natural language. Spatial language is used to describe many mathematical processes, including number sequencing (P. Watson et al. 2006). In English, the spatial prepositions have many important mathematical functions (Dawe and Mulligan 1997; Jorgenson 2010; MacGregor 1990). Hence, although the effects of variation in spatial language are most discernible in the overtly spatial areas of mathematics, the implications of this variation extend to numerical and algebraic thinking.

Spatial cognition and language are also widely perceived in the research literature as strengths for Indigenous students. From her survey of Indigenous measurement concepts from different languages, Harris (1991) concluded that "Aboriginal languages have a very rich vocabulary for expressing ideas about spatial relations" (p. 44). Studies of spatial knowledge of Indigenous Australians include dead reckoning by the Pintubi (Lewis 1976) and the visual-spatial memories of Indigenous desert children (Kearins 1976, 1981). A key piece of research was Laughren's (1978) observation that cardinal directions such as north, south, east and west form a grammatical category in Warlpiri (a language of Central Australia). Laughren also found that pre-school age children use these directions confidently. Harris also noted the use of cardinal direction by very young Warlpiri children, less than 2 years old, in small-scale space. Graham (1988) noted that Indigenous children living on the coast indicated direction differently from the desert children described by Laughren (1978). More recently, children who are monolingual speakers of Warlpiri and Anindilyakwa (a language spoken on the Northern Territory's Groote Eylandt) have been found to use spatial strategies rather than counting strategies in a non-verbal addition task (Butterworth et al. 2011).

Spatial cognition has often been assumed to be based on a natural, innate perception of the world (e.g. Piaget and Inhelder 1948/1956). However, Laughren's (1978) article also helped to stimulate a body of cross-linguistic investigation into the language of space by the Cognitive Anthropology Research Group (CARG) from the Max Planck Institute of Psycholinguistics (MPI) (Pederson et al. 1998). Their investigations found 
unexpected differences in the ways that peoples around the world talk and think about space and location, and in particular in how people describe where things are in relation to each other in a horizontal plane, or spatial frames of reference. They found that there were three frames of reference - intrinsic, absolute and relative - and that languages differ in which frames they use and in how they use them (Pederson et al. 1998; Levinson 2003). They also demonstrated links between preferred frame of reference and spatial memory (Pederson et al. 1998). Important terminology used in the literature includes the distinction between figure and ground. The figure is a salient object, potentially moveable, and the ground is a reference object with respect to which the figure is located (Talmy 1983). The following descriptions of the three frames of reference are from Levinson (2003).

In the intrinsic frame of reference, the location of the figure is described with respect to a part or facet of the ground, for example, "the pen is beside the cup." The description is scene internal, and can be rotated with respect to the viewer and the wider world without the description being invalidated. Key English terms are front, back and sides. However, if the ground object is rotated, the description is invalidated. The intrinsic frame of reference seems to be the only one that is present in all languages and is generally the first acquired by children.

In the relative frame of reference, the point of view and body of the speaker are used to relate the figure to the ground, for example, "the pen is to the left of the cup." Key English terms are in front of, behind, to the left of and to the right of, where these are from the speaker's perspective. In this reference frame, the ground object can be rotated and the same description still holds. However, if the viewer or whole scene rotates, it is invalidated. Terminology used in this frame of reference is often derived from the intrinsic. In "my left hand," left is intrinsic, but in "the pen is to the left of the cup" it is not the cup's own left we are talking about, it is a zone that has been projected from the speaker.

In the absolute frame of reference, the location of the figure is described in relation to a fixed direction or landmark, for example, "the pen is to the north of the cup". This frame of reference holds under the rotation of both the viewer and/or the ground.

Patterns of use of the frames of reference in different languages tend to be linked to context. English has all three frames of reference. In small-scale space, speakers of European languages such as English tend to prefer the relative over both the absolute and the intrinsic (Barton 2009; Levinson 2003). The absolute is generally used only in large-scale spatial description, such as reading maps. As Levinson (2003) declares, "in English or Dutch, both relative and intrinsic frames of reference are available and colloquially used, but the relative frame of reference is clearly predominant for most kinds of spatial description" (p. 179; cf. van Staden et al. 2006).

Many Australian languages prefer the use of the absolute frame of reference even in small-scale space and have very little or no use of the relative frame of reference (e.g., Haviland 1993, 1998; Meakins 2011; Wilkins 2006). 'Left' and 'right' are restricted to body parts. The use of cardinal directions in Warlpiri (Laughren 1978; Harris 1991) is the use of the absolute frame of reference. However, some Australian languages rely predominantly on the use of the intrinsic frame of reference in small-scale space (e.g. McGregor 2006; Schultze-Berndt 2006).

In many languages, the terms 'in front' and 'behind' can be used both intrinsically and relatively, with the relative sense derived from the intrinsic ones (Levinson 2003). Research on European languages shows the intrinsic sense acquired first and the 
relative sense acquired between 4 and 11 years of age (Johnston and Slobin 1979). This paper focusses on the different contexts in which the intrinsic and relative frames of reference can be used with these terms in Iwaidja and Minjilang English compared with Standard Australian English.

\section{The man and tree game}

The task reported upon here is a card-matching barrier activity for two participants which was designed to elicit uses of spatial frame of reference in speech. It has been used in several variations with different language groups in different parts of the world (e.g. Levinson and Wilkins 2006; Pederson et al. 1998).

The stimuli were two identical sets of 16 cards. The Director chose one card at random and described it to the Matcher. The Matcher, who had the cards laid out before them, tried to find the matching card. The Matcher was free to ask questions at any point. The game continued for as long as required to match all the cards. The card set was reduced for use with the child participants to six, ten or 12 cards, depending on the age of the child, and the atmosphere of the research session. Participants varied widely in how difficult they found the task. On the whole, the children found the task easier than the senior adults due to the smaller card sets, and also perhaps because of grater familiarity with the format of the task. Hence the task generated more extensive discussion between the senior participants than between the children, although all groups questioned each other.

The cards showed photos of one faceted object, a toy man, and one non-faceted object, a toy tree. The set of 16 cards used was developed by Ann Senghas to show all possible arrangements of the man and tree in the horizontal plane at right angles (Terrill and Burenhult 2008). Each photo showed the same man and tree in a different spatial arrangement; the man situated behind, in front of or on either side of the tree, and looking at the tree, facing away from it or with it at his side. Since the man is oriented by virtue of his facets (front, back, sides), he tends to operate as the figure in descriptions, while the tree serves as the referential ground (Talmy 1983).

The cards are named $R x y$, where $x$ refers to the facing direction of the man and $y$ to where he stands in relation to the tree. For example, R1 $x$ refers to any card where than man is facing the viewer. All the cards can be described using more than one frame of reference. This paper considers speakers' descriptions of the eight cards where the man is either facing the tree or has his back to the tree, that is, cards R11, R13, R22, R24, R31, R33, R42 and R44.

Much of the published data on this task uses a smaller six-card set which included cards R22, R24 and R44 (e.g. Levinson and Wilkins 2006). Thus, descriptions of cards $\mathrm{R} 11, \mathrm{R} 13, \mathrm{R} 31$ and R33 are not provided in the comparison literature.

\section{Participants}

The task was conducted with three groups of participants: senior Iwaidja language consultants directing their peers, caregivers (parents/grandparents) directing their children, and children directing their peers or caregivers. 
There were eight senior consultants who provided a benchmark of previously undocumented Iwaidja spatial language. The task was conducted seven times, with each speaker having a turn to direct except for one who performed only the role of Matcher. They were all fluent first native speakers of Iwaidja and spoke between them a range of other languages, including Mawng and Kunwinjku, and some of them could also understand the nearly extinct Amurdak and Marrku languages. They had varied levels of English proficiency. As recognised experts in the Iwaidja language, the senior consultants are identified by name with their permission, except two who did not want their names used and who were also caregivers of the child group. Table 1 shows a list of senior consultants.

There were five caregivers, three men and two women, who directed their children in Iwaidja. They were invited to participate because they were reported by the senior consultants to speak Iwaidja to their children. Caregiver1 and Caregiver2 were also senior consultants. Table 2 shows a list of the caregivers, including main languages other than Iwaidja used in the home.

The third group was eight children in four pairs speaking English and/or Kunwinjku directing each other. The children each had a turn at directing, although in some cases they swapped roles every few cards rather than after a complete turn. Table 3 shows the children who participated in the Man and Tree task, showing the main languages spoken at home and their caregivers where relevant.

All the children except Liam have an Iwaidja speaking parent, although they generally speak Kunwinjku or Mawng in the home. Liam speaks only English, as do his parents. The children who also had participating caregivers were invited to participate because they were reported by the senior consultants to understand some Iwaidja. Bianca, Aidan and Liam were invited to participate because they were present at school and had a parent present to give permission. There was only one girl in the group. There are few girls in this age group on Croker Island. This appears to be normal variation within a small population. The children varied widely in their engagement and achievement with school mathematics.

\section{Findings}

The analysis presented here is concerned with the contexts in which relative and intrinsic interpretations of key spatial terms are permissible in Iwaidja and Minjilang English. The

Table 1 List of senior consultants

\begin{tabular}{|c|c|c|c|}
\hline Name & Initials & Age in 2010 & Sex \\
\hline Khaki Marrala & $\mathrm{KM}$ & 82 & M \\
\hline Charlie Mangulda & $\mathrm{CM}$ & 75 & M \\
\hline Rae Girribuk $^{\dagger}$ & RG & 73 & $\mathrm{~F}$ \\
\hline Caregiver1 & $\mathrm{C} 1$ & - & M \\
\hline Joy Williams ${ }^{\dagger}$ & JW & 64 & $\mathrm{~F}$ \\
\hline David Galak & DG & - & M \\
\hline Maggie Marburrunbi & $\mathrm{MM}$ & - & $\mathrm{F}$ \\
\hline Caregiver2 & $\mathrm{C} 2$ & - & $\mathrm{F}$ \\
\hline
\end{tabular}

${ }^{\dagger}$ Signifies deceased 
Table 2 List of caregivers

\begin{tabular}{llll}
\hline Pseudonym & Initials & Sex & Other languages spoken at home \\
\hline Caregiver1 & C1 & M & Kunwinjku \\
Caregiver2 & C2 & F & English, Mawng \\
Caregiver3 & C4 & M & Mawng \\
Caregiver4 & C5 & M & Mawng \\
Caregiver5 & C3 & F & Kunwinjku \\
\hline
\end{tabular}

Iwaidja terms are wurdaka 'in front, first, go before' and warrwak 'behind.' Wurdaka is a verb and warrwak is an adverb. They both have temporal as well as spatial meanings, so that wurdaka can mean 'earlier' and warrwak 'after, later.' The English terms are in front or simply front, and behind and back in the sense of 'at the back.'

The results consist of examples which show permissible contexts for the key terms. Many variables in the small data sets make presenting quantitative results both complex and statistically insignificant. Some of the uses occurred only once in the context amongst the speakers of the group. However, even single examples can demonstrate the permissibility of utterances in a language.

The senior adult data provides the benchmark for "proper" Iwaidja spoken fluently to a peer. Developmental factors can be assumed not to affect this data. The data provides the terms of comparison for the analysis of the children's speech. The examples show wurdaka 'in front' and warrwak 'behind' can be used intrinsically in contexts in which in front and behind are unlikely or impermissible in Standard Australian English.

The caregiver data, that is, examples of directions given by caregivers to children, introduces developmental and fluency factors. It reflects the caregivers' expectations about what the children are able to understand, including expectations about the children's conceptual development and about the children's understanding of Iwaidja. The broader study showed differences between senior adult-to-peer spatial language and caregiver-to-child language, including differences in the speech of Caregiver1 and Caregiver2 who participated in both groups. For example, the use of the absolute frame of reference was frequent and widespread amongst the senior adults, but minimal in the caregiver-to-child interactions.

Table 3 List of children

\begin{tabular}{llllll}
\hline Pseudonym & Year of birth & Age at activity (year: month) & Sex & Other languages spoken at home & Caregiver \\
\hline Thomas & 2003 & 8.3 & M & English, Mawng & C2 \\
Riley & 2001 & 10.2 & M & Kunwinjku & C3 \\
Nathan & 2001 & 10.2 & M & Mawng & C5 \\
Travis & 2000 & 10.6 & M & Mawng & C4 \\
Bianca & 1999 & 11.5 & F & Kunwinjku, English & - \\
Aidan & 1999 & 11.5 & M & Kunwinjku, English & - \\
Kyle & 1999 & 12.2 & M & Kunwinjku & C1 \\
Liam & 1999 & 12.2 & M & English & -
\end{tabular}


However, the examples presented here show that caregivers expected the children to understand the key terms wurdaka 'in front' and warrwak 'behind' in most of the same contexts that the senior adults used them between themselves.

Finally, the child data shows children's uses of (in) front and behind / back in English and within Kunwinjku sentences. The examples show that some children's uses of the key English locational terms more closely parallel the uses of related terms in Iwaidja than their uses in Standard Australian English.

The results do not prove that the use of these words in Minjilang English is a direct adoption from Iwaidja. However, the results suggest an influence from Iwaidja and / or a semantically related language upon Minjilang English. There is no published data on spatial frame of reference in Mawng or Kunwinjku. Mawng, which is fairly closely related to Iwaidja, has terms warrwak 'later, last' (an adverb) and uraka 'first, in front' (a verb) which have a common historical origin with the equivalent Iwaidja terms (Singer 2006). Kunwinjku is only distantly related to Iwaidja. Equivalent terms are yungkih 'first, in front' and galuk 'after, later,' which are both adverbs (Evans 2003).

Examples in Iwaidja and Kunwinjku are shown in four lines. The first line shows the sentence or phrase in the standard orthography. The second line shows each word, with hyphens separating morphemes (meaningful word parts). The third line is an aligned morpheme-by-morpheme English gloss. Where the Iwaidja or Kunwinjku word is translated by more than one English word, but these cannot be separated morphemically in the original, the English words are separated by a period. For example, wurdaka 'in front' can be separated into $w$ 'he/she/it' and urdaka 'in front.' Because the 'in' and 'front' cannot be separated in Iwaidja, w-urdaka is glossed 'he-in.front' (for the man) or 'it-in.front' (for the tree). The final line shows a free English translation of the sentence or phrase. All transcriptions and translations were done with the assistance of fluent native speakers.

Examples for the senior consultants are referenced as (file name, time code for start of example in minutes and seconds, speaker initials, card number). For example, (dvR_101115_02, 13:33, CM, R12). Caregiver and child examples are referenced (speaker initials, card number).

Intrinsic and relative frames of reference in Iwaidja: senior speakers

Some of the senior adults, who were working with the full 16-card set, found the task challenging and to match one card sometimes took several minutes of talking. This elicited a rich and extensive range of uses of all three frames of reference.

As in English, the Iwaidja terms wurdaka 'in front', and warrwak 'behind' can have both relative and intrinsic meanings. Warrkbi wurdaka 'the man is in front' can describe a situation where the man is in front of the tree with respect to the viewer or where the man is in front of the tree by virtue of having his back to it. These are both true in R13 (Fig. 1), where both the intrinsic and the relative senses of the terms hold, reinforcing each other.

Similarly, in R11 the man is both intrinsically and relatively warrwak 'behind.' Where the intrinsic and relative frames of reference reinforce each other, the actual 


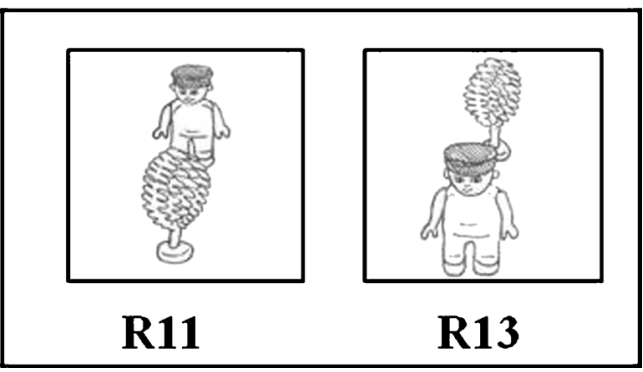

Fig. 1 Man and tree images R11 and R13

frame of reference used by the speaker was ambiguous. An example of a description of R11 is given in [1] and an example of a description of R13 is given in [2].

[1]

Wurdaka arlirr ari wurdaka ari janad ari warrwak, arildurlkung.

$\begin{array}{llllll}\text { w-urdaka } & \text { arlirr } & \text { ari } & \text { w-urdaka lda janad ari } \\ \text { it-in.front } & \text { tree } & \text { it.stands } & \text { it-in.front and he } & \text { he.stands } \\ \text { warrwak } & \text { ari-ldurlkung } & & \\ \text { behind } & \text { towards.he.to.it-behind }\end{array}$

[2]

Arlirr ari warrwak, warrkbi ari wurdaka.

$\begin{array}{llllll}\text { arlirr } & \text { ari } & \text { warrwak } & \text { warrkbi } & \text { ari } & \text { w-urdaka } \\ \text { tree } & \text { it.stands } & \text { behind } & \text { man } & \text { he.stands } & \text { he-in.front }\end{array}$

'The tree is standing behind, the man is standing in front.' (C1, R13)

These uses of the terms in [1] and [2] are similar to uses of in front and behind in English, and their use in these contexts was not surprising in the Iwaidja data.

More surprising, to an English speaker, was the use of these terms about cards where the man and tree were arranged on the lateral across-axis of the cards, and thus were beside each other from the viewer's perspective. The man was described as being wurdaka 'in front' of the tree in cards R24 and R42 (Fig. 2) by virtue of having his back to it. Examples of descriptions of these cards are given in [3] and [4] respectively.

[3]

Kabanayan baraka warrkbi ari wurdaka Ida arlirr warrwak?

$\begin{array}{llllll}\text { kaban-ayan } & & \text { baraka } & \text { warkbi } & \text { ari } & \text { w-urdaka } \\ \text { you.to.it-see } & & \text { that } & \text { man } & \text { he.stands } & \text { he-in.front } \\ \text { lda } & \text { arlirr } & \text { warrwak } & & & \\ \text { and } & \text { tree } & \text { behind } & & & \end{array}$

'Can you see the one where the man is standing in front and the tree is behind?' (dvR_100522, 17:16, JW, R24) 


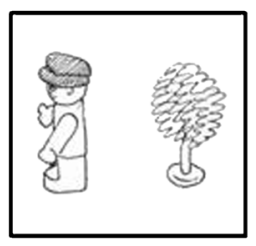

R24

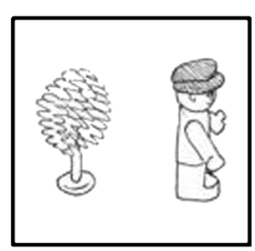

R42

Fig. 2 Man and tree images R24 and R42

[4]

Warrkbi wurdaka, arlirr ari rukung bungkurryuwu warrwak.

$\begin{array}{llllll}\text { warkbi } & \text { w-urdaka } & \text { arlirr } & \text { ari } & \text { r-ukung } & \text { bungkurryuwu } \\ \text { man } & \text { he-in.front } & \text { tree } & \text { it.stands } & \text { he.to.it-gives } & \text { nape.of.neck } \\ \text { warrwak } & & & & \\ \text { behind } & & & & \end{array}$

'The man is in front, the tree, he gave the back of his neck to it, (it's) behind.' (C2, R42)

Similarly, the man was described as being warrwak 'behind' the tree in cards R22 and R44 (Fig. 3) by virtue of facing it. Examples of descriptions of these cards are given in [5] and [6] respectively.

[5]

Ari wurdaka wuka makumbu baraka arlirr, ba warrkbi ari wuka warrwak.

ari

it.stands

w-urdaka

wuka

makumbu

ba

it-in.front

at

south

baraka

arlirr

ba

warrkbi

ari

the

man

he.stands

wuka

that

tree

'It stands in front to the south, that tree, the man stands behind.' (dvR_101115_04, 03:08, KM, R22)

[6]

Arlirr wurdaka lda ba warrkbi, ari rukung rtamburryak, rayan ba arlirr.

\begin{tabular}{|c|c|c|c|c|c|c|c|}
\hline arlirr & $w$-urdaka & & $l d a$ & $b a$ & warrkbi & & $\begin{array}{l}\text { r-ukung } \\
\text { he.to.it-giv }\end{array}$ \\
\hline & it-in.front & & and & the & man & he.stands & he.to.it-gi \\
\hline $\begin{array}{l}\text { rtamburryak } \\
\text { chest }\end{array}$ & & $\begin{array}{l}r \text {-ayan } \\
\text { he.to.it-looks }\end{array}$ & & $\begin{array}{l}b a \\
\text { the }\end{array}$ & $\begin{array}{l}\text { arlirr } \\
\text { tree }\end{array}$ & & \\
\hline
\end{tabular}

'The tree is in front and the man is giving his chest (facing it), looking at the tree.' (dvR_100522, 44:13, MM, R44)

In examples [3] through [6] only the intrinsic senses of the terms hold. In (Standard) English, similar descriptions are unlikely or impossible (Pederson 2006). Standard 


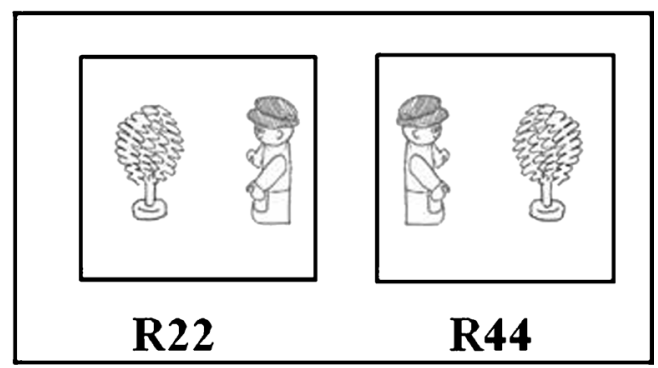

Fig. 3 Man and tree images R22 and R44

English might permit the tree to be 'behind the man' in $R 24$ and $R 42$, and 'in front of the man' in $R 22$ and $R 44$, but it does not permit the man to be 'in front of the tree' in $R 24$ and $R 42$ nor 'behind the tree' in $R 22$ and $R 44$. Pederson explains that in Tamil, where similar descriptions to examples [3] through [6] are permissible, the orientation of the faceted figure creates an ascribed intrinsic reference through the projection of an oriented line from the figure which then applies to the tree.

Warrwak 'behind,' which is an adverb, was sometimes accompanied by a verb also meaning 'to be behind' such as ldurlkung in [1] above, used about card R11. It was also used about R22. Ldurlkung 'to be behind' is a transitive verb and makes it clear that that he is behind $i t$.

Even more interesting were some of the descriptions by senior speakers of cards $R 31$ and $R 33$ (Fig. 4). In these cards, the intrinsic and the relative descriptions are in direct contradiction.

Some speakers gave descriptions that used the relative frame of reference. An example for R31 is given in [7] and one for R33 in [8].

[7]

Ruka arlirr wurdaka warrkbi warrwak arrumbukung bungkurryuwu.

$\begin{array}{llllll}\text { ruka } & \text { arlirr } & \text { w-urdaka } & \text { warrkbi } & \text { warrwak } & \text { arrumb-ukung } \\ \text { this } & \text { tree } & \text { it-in.front } & \text { man } & \text { behind } & \text { he.to.us-gives }\end{array}$

bungkurryuwu

nape.of.neck

'In this one, the tree is in front and the man is behind, with his back to us.' (C2, R31)

[8]

Badba warrkbi wurdaka, maitbi angmungurlkbarrki or kindi, arlirr ari wuka warrwak.

\begin{tabular}{|c|c|c|c|c|c|c|}
\hline$b a d b a$ & warrkbi & & w-urdaka & maitbi & & angmu-ngurlkbarrki \\
\hline next & $\operatorname{man}$ & & he-in.front & might.be & & he.to.it-look.at.ground \\
\hline O & kindi & arlirr & ari & wuka & warrwak & \\
\hline & what & tree & it.stands & at & behind & \\
\hline
\end{tabular}

'In this one the man is in front, might be looking down or something, the tree is there behind.' (dvR_100522, 36:00, MM, R33) 


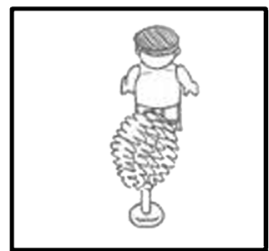

R31

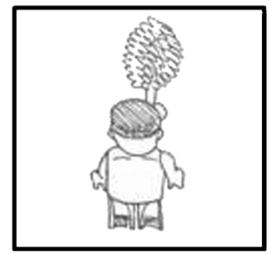

R33

Fig. 4 Man and tree images R31 and R33

Like [1] and [2], examples [7] and [8] are not surprising to an English speaker. However, some speakers used the intrinsic frame of reference to describe the same cards. An example for R31 is given in [9] and for R33 in [10].

[9]

Warrkbi wurdaka lda arlirr warrwak.

warrkbi

w-urdaka

$l d a$

arlirr

warrwak.

man

he-in.front

and

tree

behind

'The man is in front and the tree is behind.' (dvR_100513 45:02 RG, R31)

[10]

RG:

Arrumbukung bungkurryuwu. Ari yangbayan yawurrakan rayan jamin.

C2:

Arlirr wurdaka?

RG:

Arlirr wurdaka.

arrumb-ukung

he.to.us-gives

yaw-urrakan

away.he.to.it-stares

bungkurryuwu

ari

nape.of.neck

he.stands

yangb-ayan

$\begin{array}{lll} & \text { rayan } & \text { jamin } \\ \text { he.to.it-looks } & \text { it.to.him.in } \\ \text { w-urdaka } & \text { arlirr } & \text { w-urdaka } \\ \text { it-in.front } & \text { tree } & \text { it-in.front } \\ \text { 'He's got his back to us. He's looking away, staring at it.' } \\ \text { 'The tree is in front?' } \\ \text { 'The tree is in front.' (RG \& C2, R33) }\end{array}$

Examples [9] and [10] show that Iwaidja permits intrinsic as well as relative descriptions in the contexts of R31 and R33. Most of the published material on the Man and Tree task refers only to descriptions of cards where the man and tree are standing on the left-right axis (as in cards R22, R24, R42 and R44) and does not discuss intrinsic descriptions such as in [9] and [10]. However, the relative frame of reference appears to be the default in these contexts in English (Levinson 2003). In Standard Australian English, descriptions such as [9] and [10] are unlikely and would need to be qualified by a relational phrase, such as saying "the tree is in front of the man" about R33. 
Note that the intrinsic use in the context of R31 and R33 differs from the wellknown Hausa pattern, which is a relative use of similar terms, but reversed from English such that the object further from the speaker is described as 'in front' and the object closer to the speaker is described as 'behind' (Hill 1982). If the Hausa pattern applied, one would be able to say warrkbi wurdaka, arlirr warrwak 'the man is in front, the tree is behind' about R11, or arlirr wurdaka, warrkbi warrwak 'the tree is in front, the man is behind' about R13, neither of which are valid Iwaidja sentences for these cards.

Intrinsic and relative frames of reference in Iwaidja: adult to child

Smaller card sets and more familiarity with the type of task on the part of the children meant that matches were made from briefer descriptions by the caregivers than with the senior adults. The overall study showed less use of the absolute frame of reference and more use of the relative frame of reference for adult caregivers directing their children compared to senior adults directing their peers.

However, the contexts in which the caregivers used wurdaka 'in front' and warrwak 'behind' intrinsically and relatively while directing the children largely paralleled the uses of the senior speakers directing their peers. Of the five caregivers, all except Caregiver3 used the terms in the task.

Like the senior adults, caregivers used the terms about R11 and R13 (Fig. 1), where both the intrinsic and relative senses of the terms are valid and reinforce each other. An example of for R13 is given in [11].

[11]

Ba arlirr warrwak and warrkbi ari angbardi.

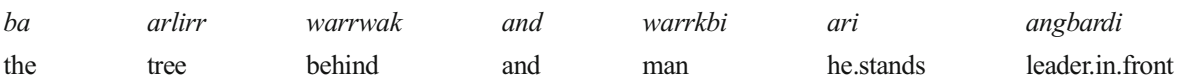

'The tree is behind and the man stands in the front.' (C5, R13)

While the senior adult descriptions of R11 and R13 in [1] and [2] were ambiguous as to actual frame of reference, since the intrinsic and relative frames of reference are both true, in [11] rather than wurdaka 'in front,' Caregiver5 uses angbardi 'harpoon man,' a term which refers to the person in the front of a boat who is fishing with a spear. Caregiver5 uses this term to refer to the man's intrinsic position in front of the tree, suggesting that warrwak 'behind' is also used intrinsically here.

Caregivers used the terms intrinsically about R24 and R42 (Fig. 2), where the man is wurdaka 'in front' with his back to the tree and the tree is warrwak 'behind'. No relative interpretation is possible since from the viewer's perspective they are beside each other. There were no examples of the caregivers using these terms to describe R22 or R44, where the tree is 'in front' and the man is 'behind'. For those cards, the caregivers described the man as looking at the tree, or having his chest towards the tree, descriptions which were also used by the senior adults. Rather than a greater likelihood of perceiving the man to be 'in front' and the tree 'behind' in R24 and R42 than of perceiving the man to be 'behind' and the tree to be 'in front' in R22 and R44, the assymmetry of use may be due to successful uses of 'looking at the tree' descriptions 
meaning that wurdaka 'in front' and warrwak 'behind' descriptions were not necessary. A much larger data set would be necessary to determine this.

Caregivers gave both intrinsic and relative descriptions of R31 and R33 using the terms.

An intrinsic description of R31 was given by Caregiver5, as shown in [12].

[12]

Warrkbi artbung ari wurdaka, arlirr bingkan warrwak.

warkbi

man

b-ingkan

it-comes

\begin{abstract}
artbung
\end{abstract}
again

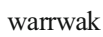

w-urdaka

he-in.front

'The man is in front again, the tree comes behind.' (C5, R31)

In [12] Caregiver5's use of the verb bingkan "it comes" gives a dynamic quality to the description of the tree's location, suggesting an ascribed intrinsic reference (Pederson 2006).

Caregiver1 gave relative descriptions of R31 and R33 using wurdaka 'in front' and warrwak 'behind.' Caregiver1 was one of the more strongly relative speakers amongst the adult participants, and his use of the relative frame of reference increased when he was directing his son compared to directing his peer. He also used relative maruj 'left' and nurlinurli 'right' to describe cards R22, R24, R42 and R44. This was a noticeable increase from his relative use of these terms in the senior data, where he used these terms to describe R42.

The children's success in matching the cards demonstrated that that the children understood the scope of the Iwaidja terms, and were able to understand the intrinsic and relative frames of reference in the correct contexts.

Child-directed uses of intrinsic and relative frame of reference

The child-directed data is drawn from a small result set with many variables. The examples show children's uses of in front or front and behind or back in English sentences and mixed into Kunwinjku sentences.

Examples [14], [15] and [16] are all descriptions of card R11, where the relative and intrinsic frames of reference reinforce each other (Fig. 1). These are like the senior example [1] and the caregiver example [11].

[14]

The man is back and the tree is front.

(Thomas, R11)

[15]

A person behind a tree facing towards me.

(Kyle, R11) 
[16]

Nungka back and kanan that gundalk kadi front.

\begin{tabular}{|c|c|c|c|c|c|}
\hline nungka & back & and & ka-nan & that & gundalk \\
\hline him & back & and & he-looks & that & tree \\
\hline$k a-d i$ & front & & & & \\
\hline it.stands & front & & & & \\
\hline
\end{tabular}

In example [14], Thomas uses back and front without prepositions which is fairly typical of Aboriginal English. In example [15] Kyle uses 'behind' in a more Standard Australian English sentence. Example [16] is in Kunwinjku with English back and front mixed in, as well as the conjunction and and the demonstrative that. The attribution of 'back' and 'front' is easy for a speaker of Standard Australian English to interpret.

Some of the children also used the terms intrinsically about cards such as R24 and R42 in which the man and tree stand on the across-axis of the card, and from the viewer's relative perspective are beside each other (Fig. 2). Examples [17] and [18] are thus like the adult examples [3] and [4].

[17]

He's facing front and the tree facing front again.

(Aidan, R42)

[18]

The tree behind the man.

(Bianca, R24)

Example [17] is another instance of ascribed orientation: Although the tree has no facets, it acquires a facing direction from its association with the man. Example [18], about card R24, and [15], about card R11, both use behind in a transitive sense, saying what the tree or man is behind. While a description such as [18] is marginal in Standard English, it is permissible in Minjilang English. In addition, the children used other intrinsic strategies to describe cards R22, R24, R42 and R44. They also gave relative descriptions of the cards, describing the man as on the left or right or beside the tree.

Like the adults, some of the children also used back and front in ways that were unambiguously relative, as in [19], about card R31 (Fig. 4).

[19]

The tree is front, the man is back.

(Nathan, R31)

Example [19] is thus like the adult examples [7] and [8]. However, other children used the terms about the same card in ways that were unambiguously intrinsic, as in examples [20] and [21]. They are thus like the adult examples [9] and [10]. 
[20]

He's in front of the tree.

(Kyle, R31)

[21]

Bininj kadi back and that gundalk kadi front.

$\begin{array}{llllll}\text { bininj } & \text { ka-di } & \text { back } & \text { and } & \text { that } & \text { gundalk } \\ \text { man } & \text { he-stands } & \text { back } & \text { and } & \text { that } & \text { tree }\end{array}$

ka-di front

it-stands front

'The man is standing in the back and the tree is standing in the front.' (Riley, R33)

There was a particularly interesting interaction between Kyle and Liam about card R31. Liam was the only child in the study who did not speak one of the local Australian languages. When it was Liam's turn to direct the task and he was describing R31 to Kyle, there was some debate between the two about 'front' and 'behind,' as shown in example [22].

[22]

Liam: Now the person, is this on the front or behind? Behind. A person behind the tree.

Kyle: I kn.., it's in front but I know what you mean.

(Kyle \& Liam,

R31)

In [22], both children demonstrate the ability to perceive both the relative and intrinsic frames of reference. Liam opts for the relative, but Kyle asserts the primacy of the intrinsic frame of reference in this situation.

All the children except Aidan used relative strategies some of the time. Relative back and front were used by Nathan, Liam and Bianca and relative left, right or beside / side were used by Kyle, Liam, Aidan, Bianca and Thomas. This was a greater use of the relative frame of reference than in the adult Iwaidja data.

The children's uses of intrinsic in front / front and behind / back for standing arrangements on the across-axis (cards R22, R24, R42 and R44) and where the intrinsic sense is in direct contradiction to the relative one (cards R31 and R33) show more similarity with the ways wurdaka 'in front' and warrwak 'behind' are used in Iwaidja than with the ways these words are used in Standard Australian English. In these intrinsic descriptions, the children's attention is on the front and back of the toy man in the cards, and his position with respect to the tree, than to his position from their own viewpoint.

Although the children were using English words in English and Kunwinjku sentences, their uses of these words paralleled the uses of their parents and grandparents directing them in Iwaidja. It appears likely that the scope of similar words in Kunwinjku resembles Iwaidja rather than English, although use of frame of reference in Kunwinjku has not yet been investigated. The scope of use of in front / front and behind / back in Minjilang English seems to have been influenced by local Australian languages such as Iwaidja and Kunwinjku. 


\section{Discussion}

Educational responses to the differences in spatial language and cognition between speakers of Australian languages and of Standard Australian English have tended to perceive the differences as strengths (e.g. Sullivan and van Riel 2011; Willis 2005) or lacks (e.g. Jorgenson 2010; Kimberley Education District 2000). Generalities abound; for example, knowing that predominant use of the absolute frame of reference is widespread in Australian languages, Yunkaporta suggests:

Once your students understand directionality as a key part of Aboriginal placebased cultures, you have an Aboriginal perspective in play every time you ask them to "look west towards the whiteboard," or to "line up at the south door." (Yunkaporta and Kirby 2011, p. 210)

However, there are other languages such as Iwaidja where the intrinsic frame of reference is used in many contexts. Analysis of spatial language by frame of reference provides a way of understanding specifics that might need to be taken into account to understand the spatial cognition of Indigenous language-speaking students.

It is quite common for teachers of Indigenous language-speaking students to have difficulty teaching the English concepts of 'before' and 'after' in relation to numbers, for example, "What number comes after 6?" and "What number comes before 6?"; Graham (1988) notes that the translation of terms for these concepts between some Australian languages and English is context dependent and affected by the speaker's point of view. P. Watson et al. (2006) note that the mixture of spatial metaphors about the number line may be particularly confusing for students for whom English is an additional language. If directionality is projected onto numbers such that going 'before' is associated with being 'in front,' it is possible the ordinality of numbers may be seen as the inverse of their cardinality (Edmonds-Wathen 2012b). The confluence of the concepts such as 'before' and 'in front' in Australian languages such as Iwaidja creates the scope for speakers of these languages to confuse or conflate the English terms.

Because of the shared vocabulary between intrinsic and relative frames of reference in many languages including Iwaidja and English, different uses of these frames of reference depending on context can be confusing. It is quite common to teach the English concepts 'in front' and 'behind' in an early years classroom using similar toys to the task described in this paper. A teacher asking a student to place the man 'behind' the tree would be anticipating an outcome like R11, where the tree is between the speaker and the man. Any outcome where the tree is between the speaker and the man would be accepted, regardless of the facing direction of the man. A student using an intrinsic 'in front' and 'behind' could place the man as in R22, facing the tree, but to the side from a relative viewpoint, or as in R31, facing the tree, but closer to the student than the tree. The Standard Australian English-speaking teacher would be likely to say that this was wrong, and to think that the child just had not yet grasped the concept. This may then be attributed to the student's development and / or their level of fluency in English. In the study, the intrinsic uses were seen with students of varied ages, schooling and levels of English. Kyle, for example, who insisted that the man was 'in front' in R31, was 12 years old, a regular school attender and one of the students who I have seen is able to switch deliberately between Minjilang English and Standard Australian English in school assessment contexts. 
Graham (1988) points out that a failure to appreciate the subtle differences in concepts between languages can lead teachers to underrate their students' intelligence:

[C]hildren in English-only programmes, who have been intelligently applying their Aboriginal view of the world to their newly acquired English terminology have simply appeared "stupid" to teachers and others who frequently had little understanding of the difficulties children were experiencing were in making sense of what was being taught. (p. 129)

The children, however, may have difficulty in understanding why some of their uses of these words are considered wrong by their teachers and why others are accepted. In many cases, how they use and respond to 'in front' and 'behind' will concord with the understanding of the teacher. But in other cases they will be told that they are wrong. Because the differences in context are so subtle, the teachers' criticism can seem random to the student. The students' understanding can also seem random or unconsolidated to the teacher, although they are in fact demonstrating their own conceptual consistency.

Of course, it is part of the role of the teacher to teach the standard version of the mathematical language used in the classroom. Teaching the standard version of a language then overlaps with teaching the mathematical register. Teachers themselves use everyday words that also have mathematical meanings. They do not tell students that the everyday meaning is wrong; they tell them that in mathematics the term has a special meaning. With dialectal differences, there is more of a tendency for teachers to regard non-standard varieties of a language as "wrong," "poor," or "bad" (Butcher 2008). Teachers need to understand that dialectal differences are simply different, not better or worse, and then try to understand the nature of the difference (Frigo et al. 2004; Malcolm et al. 2003).

The use of the typology of spatial frame of reference offers a method to analyse the contextual differences in the ways that languages use these concepts. However, an understanding that wurdaka 'in front' and warrwak 'behind' can be used in the strongly intrinsic manner reported here may help the teacher to understand what the student is doing. They can then explain to the student that that in Standard Australian English these terms do not have the same range of meanings as in Iwaidja (or Kunwinjku). The teacher is able to be explicit about differences between the Indigenous view and the Western one only when the teacher is themself aware of the differences.

Then teachers will be in a position to be explicit about the differences between Aboriginal English and Standard Australian English with their students. For example, when Kyle says about the man in R31, "he's in front of the tree," the teacher could reply, "yes, he's in front of the tree from his perspective. From mine, he's behind the tree." This could be elaborated with the explanation that in Standard Australian English, it is the speaker's perspective that is assumed unless an intrinsic perspective is explicitly specified.

\section{Conclusion}

This paper has focussed on different uses of intrinsic and relative spatial frames of reference in Minjilang English, influenced by Iwaidja or other Australian languages, and Standard Australian English. It is a difference that has significance in the 
classroom. Being aware of this difference may help Standard Australian Englishspeaking teachers of Indigenous language-speaking students in the community where the research was undertaken. It is also a difference that may exist in other communities, among other language groups. Analysing this difference in terms of spatial frames of reference has enabled a description of the variation in talking about spatial location between languages which does not privilege one way of structuring and talking about space over another, but which enables different ways of talking to be compared on equal terms. It is more than likely that there are many other ways in which the home language and worldview of Indigenous students influences their use of mathematical terms, ways that are also so subtle that they can be difficult to identify in classroom practice and observation.

Research tools from cognitive linguistics were used to elicit the differences described in this paper. These linguistic techniques have thus far been little applied in the mathematics education context, but offer a rich opportunity to investigate links between language and cognition, and to describe what is going on with children's spatial language. There is scope for further investigations of this type in other languages as well as for ethnographic research in the same community, which might offer an explanation of why a group of people talk in the way they do. Teachers and researchers might think about cultural values and how they might inform linguistic patterns. This must be done carefully however, without assuming that there is anything natural or normal about the way Standard Australian English talks about space.

The challenge remains of how teachers in remote Indigenous communities who are under pressure to improve their students' performance on numeracy tests written in English can gain an understanding of their students' spatial language and thinking. Teachers might look for patterns of use of mathematical terms that do not seem to be consistent. The uses may well be consistent from the students' perspective. It is also extremely important that teachers do not dismiss dialectal differences as "bad" speech if they want to encourage their students to appreciate different ranges of meaning for mathematical terms used in the classroom.

Acknowledgments This research was supported by a grant from the Australian Institute of Aboriginal and Torres Strait Islanders Studies and an Australian Postgraduate Award scholarship. The author wishes to acknowledge the assistance of Bruce Birch in collecting and analysing the senior adult data, and of † Joy Malwagag Williams in translating the data. Earlier versions of parts of this paper were presented at the ICMI Conference Study 21: Mathematics Education and Linguistic Diversity, September 16-20, 2011, São Paulo, Brazil (Edmonds-Wathen 2011b) and the 12th International Congress on Mathematics Education, July 8-15, 2012, Seoul, Korea (Edmonds-Wathen 2012a). Thanks to Steve Thornton, Robyn Gregson and the anonymous reviewers whose advice and feedback has improved this paper.

\section{References}

Australian Bureau of Statistics. (2011). Population characteristics, aboriginal and Torres Strait Islander Australians, 2006. Retrieved from http://abs.gov.au/ausstats/abs@.nsf/Lookup/6E6D19F5BB 55AD66CA2578DB00283CB2?opendocument.

Barton, B. (2009). The language of mathematics: Telling mathematical tales. New York: Springer.

Berry, J. W. (1985). Learning mathematics in a second language: some cross-cultural issues. For the Learning of Mathematics, 5(2), 18-23. 
Booth, R. D. L., \& Thomas, M. O. J. (1999). Visualization in mathematics learning: arithmetic problemsolving and student difficulties. The Journal of Mathematical Behavior, 18(2), 169-190. doi:10.1016/ S0732-3123(99)00027-9.

Butcher, A. (2008). Linguistic aspects of Australian Aboriginal English. Clinical Linguistics and Phonetics, 22(8), 625-642.

Butterworth, B., Reeve, R., \& Reynolds, F. (2011). Using mental representations of space when words are unavailable: studies of enumeration and arithmetic in Indigenous Australia. Journal of Cross-Cultural Psychology, 42(4), 630-638. doi:10.1177/0022022111406020.

Cognitive Anthropology Research Group at the Max Planck Institute for Psycholinguistics. (1993). Field Manual for the Space Stimuli Kit 1.2 June 1993 [Working document, used with permission]. Nijmegen: Max Planck Institute.

Cooper, T. J., Baturo, A. R., Warren, E., \& Doig, S. M. (2004). Young “white” teachers' perceptions of mathematics learning of Aboriginal and non-Aboriginal in remote communities. In M. Hoines \& A. Fuglestad (Eds.), Proceedings of the 28th Conference of the International Group for the Psychology of Mathematics Education, volume 1 (pp. 239-246). Bergen: Bergen University College.

Cummins, J. (1979). Linguistic interdependence and the educational development of bilingual children. Review of Educational Research, 49(2), 222-251. doi:10.3102/00346543049002222.

Cummins, J. (1989). A theoretical framework for bilingual special education. Exceptional Children, 56, 111119.

Dawe, L., \& Mulligan, J. (1997). Classroom views of language in mathematics. In B. Doig, J. Lokan, \& Australian Council for Educational Research (Eds.), Learning from children: Mathematics from a classroom perspective (pp. 7-35). Melbourne: Australian Council for Educational Research.

Devlin, B. (2011). A bilingual education policy issue: Biliteracy versus English only literacy. In N. Purdie, G. Milgate, \& H. R. Bell (Eds.), Two way teaching and learning: Toward culturally reflective and relevant education (pp. 49-69). Melbourne: Australian Council for Educational Research.

Edmonds-Wathen, C. (2011a). Locating the learner: Indigenous language and mathematics education. In J. Clark, B. Kissane, J. Mousley, T. Spencer, \& S. Thornton (Eds.), Mathematics: Traditions and [new] practices: Proceedings of the 34th annual conference of the Mathematics Education Research Group of Australasia and the Australian Association of Mathematics Teachers (pp. 217-315). Adelaide: AAMT and MERGA.

Edmonds-Wathen, C. (2011b). What comes before? Understanding spatial reference in Iwaidja. In M. Setati, T. Nkambule, \& L. Goosen (Eds.), Proceedings of the ICMI Study 21 Conference: Mathematics and language diversity (pp. 89-97). São Paolo: ICMI.

Edmonds-Wathen, C. (2012a). False friends in the multilingual mathematics classroom. Paper presented at the 12th International Congress on Mathematical Education Topic Study Group 28, 8-15 July, 2012, Seoul, Korea.

Edmonds-Wathen, C. (2012b). Spatial metaphors of the number line. In J. Dindyal, L. P. Cheng, \& S. F. Ng (Eds.), Mathematics education: Expanding horizons (Proceedings of the 35th Annual Conference of the Mathematics Education Research Group of Australasia) (pp. 250-257). Singapore: MERGA.

Evans, N. (2003). Bininj Gun-Wok: A pan-dialectal grammar of Mayali, Kunwinjku and Kune. Canberra: Pacific Linguistics, Research School of Pacific and Asian Studies, Australian National University.

Evans, N. (2010). Dying words: Endangered languages and what they have to tell us. Chichester: WileyBlackwell.

Frigo, T., Corrigan, M., Adams, I., Hughes, P., Stephens, M., \& Woods, D. (2004). Supporting English literacy and numeracy learning for Indigenous students in the early years. Melbourne: Australian Council for Educational Research.

Graham, B. (1988). Mathematical education and Aboriginal children. Educational Studies in Mathematics, 19(2), 119-136.

Harris, P. J. (1991). Mathematics in a cultural context: Aboriginal perspectives on space, time and money. Geelong: Deakin University.

Haviland, J. B. (1993). Anchoring, iconicity, and orientation in Guugu Yimithirr pointing gestures. Journal of Linguistic Anthropology, 3(1), 3-45. doi:10.1525/jlin.1993.3.1.3.

Haviland, J. B. (1998). Guugu Yimithirr cardinal directions. Ethos, 26(1), 25-47.

Hill, C. (1982). Up/down, front/back, left/right: A contrastive study of Hausa and English. In J. Weissenborn \& W. Klein (Eds.), Here and there: Cross-linguistic studies on deixis and demonstration (pp. 11-42). Amsterdam: John Benjamins.

Huttenlocher, J. (1968). Constructing spatial images: a strategy in reasoning. Psychological Review, 75(6), 550-560. doi:10.1037/h0026748.

Iwaidja Inyman [Online] (2010). Retrieved 23 February 2012 from http://www.iwaidja.org/. 
Johnston, J. R., \& Slobin, D. I. (1979). The development of locative expressions in English, Italian, SerboCroatian and Turkish. Journal of Child Language, 6, 529-545.

Jorgensen (Zevenbergen), R. (2011). Group work, language and interaction: Challenges of implementation in Aboriginal contexts. In L. Sparrow, B. Kissane, \& C. Hurst (Eds.), Shaping the future of mathematics education: Proceedings of the 33rd annual conference of the Mathematics Education Research Group of Australasia (pp. 740-743). Freemantle: MERGA.

Jorgenson, R. (2010). Issues of social equity in access and success in mathematics learning for Indigenous students. Paper presented at the Teaching mathematics? Make it count: What research shows us about effective mathematics teaching and learning conference, Melbourne, 16 August. Retrieved from http:// www.acer.edu.au/conference/2010.

Kearins, J. (1976). Skills of Aboriginal desert children. In G. E. Kearney \& D. W. McElwain (Eds.), Aboriginal cognition: Retrospect and prospect (pp. 199-212). Canberra: Australian Institute of Aboriginal Studies.

Kearins, J. M. (1981). Visual spatial memory in Australian Aboriginal children of desert regions. Cognitive Psychology, 13, 434-460.

Kimberley Education District. (2000). Talking concepts: The language of Western mathematics, science and instruction. Perth: Education Department of Western Australia. Retrieved from http://www.eddept.wa. edu.au/SAEr/images/talking.pdf.

Konigsberg, P., \& Collard, G. (2002). Ways of being, ways of talk. Perth: Education Department of Western Australia.

Laughren, M. N. (1978). Directional terminology in Warlpiri (a Central Australian language). In Working papers in language \& linguistics no. 8 (pp. 1-16). Launceston: Tasmanian College of Advanced Education.

Lean, G., \& Clements, M. A. (1981). Spatial ability, visual imagery, and mathematical performance. Educational Studies in Mathematics, 12(3), 267-299. doi:10.1007/BF00311060.

Levinson, S. C. (2003). Space in language and cognition: Explorations in cognitive diversity. Cambridge: Cambridge University Press.

Levinson, S. C., \& Wilkins, D. (2006). Grammars of space: Explorations in cognitive diversity. Cambridge: Cambridge University Press.

Lewis, D. (1976). Observations on route finding and spatial orientation among the Aboriginal peoples of the Western desert region of central Australia. Oceania, 46(4), 249-282.

MacGregor, M. (1990). Reading and writing in mathematics. In J. Bickmore-Brand (Ed.), Language in mathematics (pp. 100-116). Melbourne: Australian Reading Association.

McGregor, W. B. (2006). Prolegomenon to a Warrwa grammar of space. In S. C. Levinson \& D. Wilkins (Eds.), Grammars of space: Explorations in cognitive diversity (pp. 115-156). Cambridge: Cambridge University Press.

Malcolm, I., Kessaris, T., \& Hunter, J. (2003). Language and the classroom setting. In Q. Beresford \& G. Partington (Eds.), Reform and resistance in Aboriginal education: The Australian experience (pp. 92109). Perth: University of Western Australia Press.

Meakins, F. (2011). Spaced out: inter-generational changes in the expression of spatial relations by Gurindji people. Australian Journal of Linguistics, 31(1), 43-77.

Moses, K., \& Wigglesworth, G. (2008). The silence of the frogs: Dysfunctional discourse in the 'English-only' Aboriginal classroom. In J. Simpson \& G. Wigglesworth (Eds.), Childrenś language and multilingualism: Indigenous language use at home and school (pp. 129-153). London: Continuum.

Northern Territory Department of Education and Training. (2009). Northern Territory curriculum framework English as a Second Language introduction. Retrieved from http:/www.det.nt.gov.au/teachers-educators/ curriculum-ntbos/ntcf.

Northern Territory Department of Education and Training. (2012). Framework for learning English as an additional language policy. Retrieved from http:/www.det.nt.gov.au/about-us/policies/documents/ schools/framework-for-learning-english-as-an-additional-language.

Northern Territory Government. (2009). Compulsory teaching in English for the first four hours of each school day policy. Retrieved from http:/www.det.nt.gov.au/corporate/policies/curriculum_studies/ CompulsoryEnglishFourHoursEachDay.pdf.

Pederson, E. (2006). Spatial language in Tamil. In S. C. Levinson \& D. Wilkins (Eds.), Grammars of space: Explorations in cognitive diversity (pp. 400-436). Cambridge: Cambridge University Press.

Pederson, E., Danziger, E., Wilkins, D., Levinson, S., Kita, S., \& Senft, G. (1998). Semantic typology and spatial conceptualization. Language, 74(3), 557-589.

Piaget, J., \& Inhelder, B. (1956). The child's conception of space (F. J. Langdon \& J. L. Lunzer, Trans.). London: Routledge \& Kegan Paul (Original work published 1948). 
Pimm, D. (1991). Communicating mathematically. In K. Durkin \& B. Shire (Eds.), Language in mathematical education: Research and practice (pp. 17-23). Milton Keynes: Open University Press.

Schultze-Berndt, E. (2006). Sketch of a Jaminjung grammar of space. In S. C. Levinson \& D. Wilkins (Eds.), Grammars of space: Explorations in cognitive diversity (pp. 63-114). Cambridge: Cambridge University Press.

Silburn, S. R., Nutton, G., McKenzie, J. W., \& Landrigan, M. (2011). Early years English language acquisition and instructional approaches for Aboriginal students with home languages other than English: A systematic review. Darwin: Menzies School of Health Research. Retrieved from http://www. det.nt.gov.au/_data/assets/pdf file/0020/20198/MenziesReport.pdf.

Singer, R. (2006). Agreement in Mawng: Productive and lexicalised uses of agreement in an Australian language. (Doctoral thesis, University of Melbourne). Retrieved from http://eprints.unimelb.edu.au/ archive/00003242/.

Skilbeck, M., \& Connell, H. (2003). Attracting, developing and retaining effective teachers: Australian country background report. Canberra: Commonwealth of Australia.

Standing Committee on Aboriginal and Torres Strait Islander Affairs. (2012). Our land, our languages: Language learning in Indigenous communities. Canberra: Commonwealth of Australia. Retrieved from www.aph.gov.au/Parliamentary_Business/Committees/House_of_Representatives_Committees?url=/ atsia/languages $2 /$ report.htm.

Sullivan, P., \& van Riel, N. (2011). Teaching geometry to Indigenous students to build confidence and engagement with mathematics [abstract]. Presentation given at AAMT- MERGA conference Mathematics: Traditions and New Practices, Alice Springs, 3-7 July.

Talmy, L. (1983). How language structures space. In H. L. Pick \& L. P. Acredolo (Eds.), Spatial orientation: Theory, research, and application (pp. 225-282). New York: Plenum Press.

Terrill, A., \& Burenhult, N. (2008). Orientation as a strategy of spatial reference. Studies in Language, 32, $93-$ 136.

Thornton, S., Giles, W., Prescott, D., \& Rhodes, D. (2011). Exploring the mathematical confidence of Indigenous preservice teachers in a remote teacher education program. Mathematics Education Research Journal, 23(2), 235-252. doi:10.1007/s13394-011-0013-4.

van Staden, M., Bowerman, M., \& Verhelst, M. (2006). Some properties of spatial description in Dutch. In S. C. Levinson \& D. Wilkins (Eds.), Grammars of space: Explorations in cognitive diversity (pp. 475-511). Cambridge: Cambridge University Press.

Watson, H. (1988). Language and mathematics education for Aboriginal-Australian children. Language and Education, 2(4), 255-273.

Watson, P., Partington, G., Gray, J., \& Mack, L. (2006). Aboriginal students and numeracy. Perth: Aboriginal Education and Training Council of Western Australia. Retrieved from http://www.aetcwa.org.au/files/pdf/ aboriginal_students_numeracy.pdf.

Wheatley, G. $\bar{H}$. (1998). Imagery and mathematics learning. Focus on learning problems in mathematics, 20(2/3), 65-77.

Wilkins, D. (2006). Towards an Arrernte grammar of space. In S. C. Levinson \& D. Wilkins (Eds.), Grammars of space: Explorations in cognitive diversity (pp. 24-62). Cambridge: Cambridge University Press.

Willis, S. (2005). First steps in mathematics: Space: Improving the mathematics outcomes of students. Port Melbourne: Harcourt Education.

Yunkaporta, T., \& Kirby, M. (2011). Yarning up Indigenous pedagogies: A dialogue about eight Aboriginal ways of learning. In N. Purdie, G. Milgate, \& H. R. Bell (Eds.), Two way teaching and learning: Toward culturally reflective and relevant education (pp. 205-213). Melbourne: Australian Council for Educational Research. 